T. Suzuki*, B. Maranda\#, T. Sakagami*, P. Catellier", C-Y. Couture , B.C. Carey*, C. Chalk* and B.C. Trapnell ${ }^{*,+, \S}$ Divisions of *Pulmonary Biology and ${ }^{+}$Pulmonary Medicine, Cincinnati Children's Hospital Medical Center, ${ }^{\S}$ Division of Pulmonary, Critical Care and Sleep Medicine, University of Cincinnati College of Medicine, Cincinnati, OH, USA. \#Département de Pédiatrie, Centre Hospitalier Universitaire de Québec, Université Laval, and "Anatomopathologie et Cytologie, Institut Universitaire de Cardiologie et de Pneumologie de Québec, Quebec, Canada.

Correspondence: B.C. Trapnell, Division of Pulmonary Biology, Cincinnati Children's Hospital Medical Center, 3333 Burnet Avenue, Cincinnati, OH 45229-3039, USA. E-mail: Bruce.Trapnell@cchmc.org

Support Statement: This work was supported, in part, by grants from the National Center for Research Resources (RR019498 to B.C. Trapnell in support of the Rare Lung Diseases Network), the National Heart, Lung and Blood Institute (HL085453 to B.C. Trapnell), the Division of Pulmonary Biology at the Cincinnati Children's Hospital (Cincinnati, OH, USA).

Statement of Interest: None declared.

\section{REFERENCES}

1 Trapnell BC, Whitsett JA, Nakata K. Pulmonary alveolar proteinosis. N Engl J Med 2003; 349: 2527-2539.
2 Trapnell BC, Whitsett JA. Gm-CSF regulates pulmonary surfactant homeostasis and alveolar macrophage-mediated innate host defense. Ann Rev Physiol 2002; 64: 775-802.

3 Hansen G, Hercus TR, McClure BJ, et al. The structure of the GMCSF receptor complex reveals a distinct mode of cytokine receptor activation. Cell 2008; 134: 496-507.

4 Suzuki T, Sakagami T, Rubin BK, et al. Familial pulmonary alveolar proteinosis caused by mutations in CSF2RA. J Exp Med 2008; 205: 2703-2710.

5 Sakagami T, Beck D, Uchida K, et al. Patient-derived granulocyte/ macrophage colony-stimulating factor autoantibodies reproduce pulmonary alveolar proteinosis in nonhuman primates. Am J Respir Crit Care Med 2010; 182: 49-61.

6 Sakagami T, Uchida K, Suzuki T, et al. Human GM-CSF autoantibodies and reproduction of pulmonary alveolar proteinosis. N Engl J Med 2009; 361: 2679-2681.

7 Suzuki T, Trapnell BC, Young LR, et al. Hereditary pulmonry alveolar proteinosis: pathogenesis, presentation, diagnosis, and therapy. Am J Respir Crit Care Med 2010; [Epub ahead of print DOI: 10.1164/rccm.201002-0271OC].

8 Goodall GJ, Bagley CJ, Vadas MA, et al. A model for the interaction of the GM-CSF, IL-3 and IL-5 receptors with their ligands. Growth Factors 1993; 8: 87-97.

9 Dirksen U, Nishinakamura R, Groneck P, et al. Human pulmonary alveolar proteinosis associated with a defect in GM-CSF/IL-3/IL-5 receptor common beta chain expression. J Clin Invest 1997; 100: 2211-2217.

10 Robb L, Drinkwater CC, Metcalf D, et al. Hematopoietic and lung abnormalities in mice with a null mutation of the common beta subunit of the receptors for granulocyte-macrophage colonystimulating factor and interleukins 3 and 5. Proc Natl Acad Sci USA 1995; 92: 9565-9569.

DOI: $10.1183 / 09031936.00090610$

\title{
The CIBERES Pulmonary Biobank Consortium: an opportunity for cooperative international respiratory research
}

\section{To the Editors:}

Research into the pathogenesis of diseases often requires access to appropriate tissue specimens [1]. The lung is not an easily accessible organ. Hence, respiratory research is often hampered by the lack of a large number of adequately preserved lung samples harvested from patients whose phenotype had been carefully and consistently characterised [2].

Since 2006, the Spanish government has funded a national network for respiratory research (CIBERES), which is currently formed of 34 research groups working cooperatively on the investigation of basic, clinical and epidemiological aspects of the main respiratory diseases (www.ciberes.org) [3]. To facilitate translational respiratory research, CIBERES has taken advantage of its multicentric nature and has designed, organised and established a nonprofit CIBERES Pulmonary Biobank Consortium $(\mathrm{CPBC})$ that follows the recommendations of the International Society for Biological and Environmental
Repositories [4] and Organisation for Economic Co-operation and Development [5]. The CPBC initiative is fully funded by public, competitive research funds, and is similar to the Lung Tissue Research Consortium (LTRC) sponsored by the National Institutes of Health in the USA. Its goal is to coordinate and manage the common collection of lung tissue samples and other related samples (whole blood, plasma and serum) from wellcharacterised patients in order to support studies on chronic obstructive pulmonary disease, asthma, lung cancer and other respiratory pathologies, as well as smoking effects. The text that follows describes briefly the main characteristics of the CPBC to the European community of respiratory researchers. Those interested in knowing more about the CPBC or contacting it are encouraged to visit its website (http://biobancopulmonar. ciberes.org).

The CPBC is a network currently formed by ten tertiary Spanish hospitals (see Acknowledgements section) that voluntarily joined the initiative and agreed to provide: 1) lung tissue 
samples obtained from volunteer patients undergoing lung resection surgery or lung transplant and, if possible, blood and serum samples; and 2) comprehensive clinical, functional and imaging data of these individuals. Biological specimens are processed and stored frozen in the hospital where they are obtained, under the custody of the local biobank, according to Spanish law [6]. The CPBC sample handling and storage protocols for the collection can be downloaded from the $\mathrm{CPBC}$ website. The following are routinely performed: 1) flashfreezing of lung tissue fragments in liquid nitrogen; 2) embedding of tissue in optimal cutting temperature (OCT) compound (Tissue-Tek ${ }^{\circledR}$; Sakura Finetek, Torrance, CA, USA), followed by freezing in a pre-cooled freezing medium (isopentane (2-methyl butane)); 3) RNAlater $^{\circledR}$ preservation (Ambion, Austin, TX, USA); 4) 4\% paraformaldehide fixation and OCT compound embedding of frozen tissue sections; and 5) $4 \%$ formalin fixation paraffin embedding of tissue sections. Anonymised phenotypic information is available from a secure website that is coordinated centrally by C. Villena (CIBERES, Mallorca, Spain) and includes: 1) anthropometric data, smoking history, occupational exposures and complete clinical, radiological and pathological information; 2) lung function tests, performed according to European Respiratory Society recommendations, including forced spirometry, static lung volumes, carbon monoxide diffusing capacity and arterial blood gas measurements; 3) haematological data; and 4) computed tomography scan information.

As recommend by the LTRC, the European Human Frozen Tumour Tissue Bank [7] and the National Cancer Institute [8], to ensure uniformity in the collection and management of the biological samples and clinical information recorded, the CPBC has established standard operation procedures that include specific training of the local personnel involved in each hospital and periodic on-site audits to evaluate the quality of the samples and the accuracy of the data recorded.

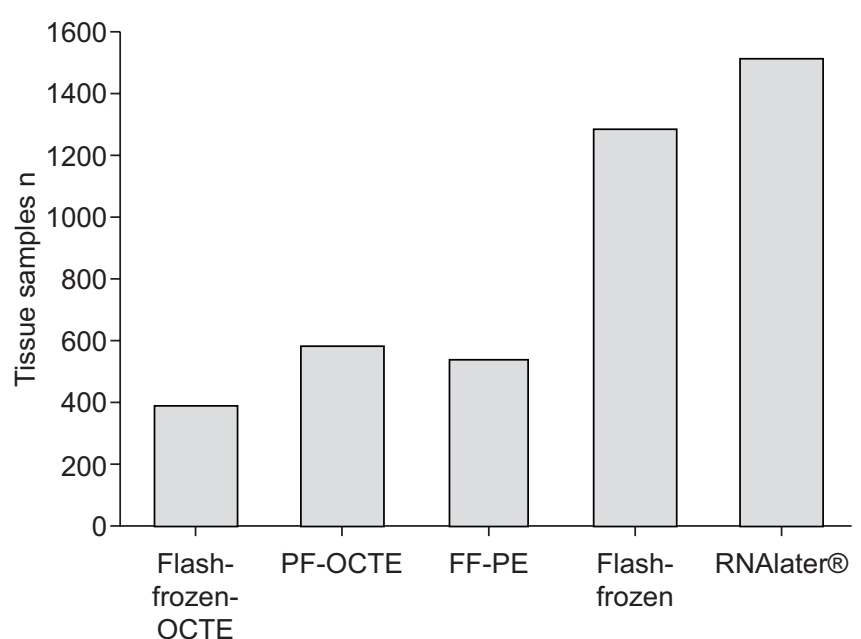

Preservation method

FIGURE 1. Number of lung tissue samples preserved following each of the five protocols used in CIBERES Pulmonary Biobank Consortium during 2009. OCTE: optimal cutting temperature (OCT) compound-embedded; PF-OCTE: $4 \%$ paraformaldehide-fixed and OCT compound-embedded; FF-PE: 4\% formalin-fixed and paraffin-embedded tissue.
One year after its launch, the CPBC has registered $>4,000$ lung tissue samples (fig. 1) that have been collected from 240 patients (table 1). The vast majority of lung tissue samples have come from surgeries for lung cancer $(77.1 \%)$, but also from lung volume reduction and other non-neoplastic surgeries $(8.8 \%)$. Blood samples are available for $37 \%$ of the recruited patients. Investigators interested in using these samples can find the requested requirements and the application form at the CPBC website. All applications must be linked to a specific and fully funded research project (that needs to be submitted for evaluation). The approval of an ethics committee is also requested. Investigators using tissue samples and clinical information from the CPBC must agree that: 1) any

TABLE 1 Main characteristics of the patients recruited into
the CIBERES Pulmonary Biobank Consortium
during 2009

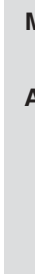

\section{Males/females}

Data not available

Age range yrs

$<30$

30-39

$40-49$

$50-59$

60-69

$>70$

Not available

BMI $\mathbf{k g} \cdot \mathbf{m}^{-2}$

$<18.5$

$18.5-24.9$

25.0-29.9

$>30$

Not available

Never-smokers

Former smokers

Current smokers

Tobacco consumption unknown

Tobacco consumption pack-yrs

Patients with COPD

GOLD stage 1

GOLD stage 2

GOLD stage 3

GOLD stage 4

Not classified

Cystic fibrosis

Asthma

Diffuse interstitial lung disease

Bronchiectasis

$\alpha_{1}$-antitrypsin deficiency

Sleep apnoea

No known respiratory comorbidities

Surgery for lung cancer yes/no

Data not available
$175(72.9) / 60(25)$

$5(2.1)$

$7(2.9)$

$4(1.7)$

$17(7.1)$

55 (22.9)

71 (29.6)

71 (29.6)

15 (6.3)

7 (2.9)

77 (32.1)

66 (27.5)

25 (10.4)

65 (25.5)

38 (15.8)

99 (41.3)

85 (35.4)

$18(7.5)$

$59.1 \pm 64.4$

74 (30.8)

9 (12.2)

31 (41.9)

11 (14.9)

$0(0.0)$

23 (31.0)

$1(0.4)$

$5(2.1)$

4 (1.7)

$4(1.7)$

$1(0.4)$

$12(5.0)$

$110(45.8)$

$185(77.1) / 21(8.8)$

$34(14.2)$
Data are presented as $n(\%)$ or mean $\pm S D$, unless otherwise stated. $n=240$ BMI: body mass index; COPD: chronic obstructive pulmonary disease; GOLD: Global Initiative for Chronic Obstructive Lung Disease. 
derived publication will explicitly mention the origin of the samples used; and 2) to return to the CPBC the raw data of their experiments, once the publication is online. This is an important and innovative condition that we hope will transform the CPBC from a passive collection of samples and information into an active and growing source of knowledge, which will be then made freely available to future users. The $\mathrm{CPBC}$, therefore, offers a unique opportunity to enhance translational research of excellence in respiratory diseases within Europe and beyond.

\section{Villena*, F. Pozo", J.A. Barberà , P. Vaquer* and}

\section{A. Agusti ${ }^{\top}$ on behalf of the CIBERES Pulmonary Biobank} Consortium (PBC) ${ }^{+}$

*Centro de Investigación Biomédica en Red de Enfermedades Respiratorias (CIBERES), Mallorca, "Hospital Universitario Doce de Octubre, Madrid, and "Servei de Pneumologia, Institut del Tòrax, Hospital Clinic-IDIBAPS, Barcelona, Spain. ${ }^{+}$The CIBERES Pulmonary Biobank Consortium (CPBC) participants are: M. Arque and C. Villena (coordinator; both Centro de Investigación Biomédica en Red de Enfermedades Respiratorias (CIBERES), Mallorca, Spain); J. Cortijo, E. Donet, R. Guijarro, G. Juan, J. Lluch and M. Martorell (all Consorcio Hospital General Universitario de Valencia, Valencia, Spain); G. Peces-Barba, G. Renedo, M.J. Rodriguez-Nieto and J. Zapatero (all Fundación Jiménez-Díaz-Capio, Madrid, Spain); J.A. Barberà, L. Molins, V. Peinado and J. Ramírez (all Hospital Clinic, Barcelona, Spain); E. Condom, S. Estany, M. Molina, J. Moya and A. Rosell (all Hospital Universitari de Bellvitge, Barcelona); E. Camarero, M. Casares, B. de Olaiz, A. Esteban, L. Fernandez- Jiménez and P. Segoviano (all Hospital Universitario de Getafe, Madrid); C. Casadevall, J. Gea, M.A. Martínez, J. Minguella and L. Pijuan (Hospital Universitario del Mar, Barcelona); E.M. Arias, A.B. Enguita, A. López-Encuentra, A. Maroto, C. Marrón, F. Pozo and J.L. Rodriguez (all Hospital Universitario Doce de Octubre, Madrid); J. Astudillo, M.T. Fernández-Figueras, E. Monsó and S. Ragull (all Hospital
Universitario Germans Trias i Pujol, Badalona, Spain); E. Canalis, I. Martín-Loeche, J. Rello, J.J. Sirvent and S. Trefler (all Hospital Universitario Joan XXIII de Tarragona, Tarragona, Spain); M. Arque, A. Carvajal, B. Cosio, C. Gómez, J. Salueda and C. Villena (Hospital Universitario Son Dureta, Mallorca).

Correspondence: A. Agusti, Institut del Tòrax, Hospital Clínic, C/Villarroel 170, Escala 3, Planta 5, 08036 Barcelona, Spain. Email: alvar.agusti@clinic.ub.es

Statement of Interest: None declared.

\section{REFERENCES}

1 Riegman $\mathrm{PH}$, Morente MM, Betsou F, et al. Biobanking for better healthcare. Mol Oncol 2008; 2: 213-222.

2 Founti P, Topouzis F, van Koolwijk L, et al. Biobanks and the importance of detailed phenotyping: a case study: the European Glaucoma Society GlaucoGENE project. Br J Ophthalmol. 2009; 93: 577-581.

3 Agusti A, Pozo F, Vaquer P. [CIBER of respiratory diseases (CibeRes)]. Arch Bronconeumol 2008; 44: 489-492.

4 ISBER, Best Practices for Repositories: Collection, Storage, Retrieval and Distribution of Biological Materials for Research. Cell Preserv Technol 2008; 6: 3-58.

5 Organisation for Economic Co-operation and Development. OECD Best Practice Guidelines for Biological Resources Centres. www. oecd.org/dataoecd/7/13/38777417.pdf Date last accessed: October 18, 2010. Date last updated: 2007.

6 LEY 14/2007, de 3 de julio, de Investigación biomédica [Biomedical Research Act 14/2007, July 3]. Boletin Oficial del Estado, 159: 28826-28848.

7 Mager SR, Oomen MH, Morente MM, et al. Standard operating procedure for the collection of fresh frozen tissue samples. Eur J Cancer 2007; 43: 828-834.

8 National Cancer Institute. Best Practices for Biospecimen Resources. http://biospecimens.cancer.gov/global/pdfs/

NCI_Best_Practices_060507.pdf Date last accessed: October 18, 2010 Date last update: June 2007.

\section{Dose-response for inhaled fluticasone on airway and systemic inflammation in COPD}

\section{To the Editors:}

Asthma is an eosinophilic condition and, as such, responds readily to inhaled corticosteroids (ICS). By contrast, chronic obstructive pulmonary disease (COPD) is a heterogeneous condition associated with neutrophilic inflammation, which is relatively steroid-insensitive. Corticosteroid/long-acting $\beta$ agonist combination inhalers improve quality of life and lung function, and reduce COPD exacerbation [1]. A meta-analysis of COPD studies has reported a $25 \%$ reduction in all-cause mortality using ICS, but dose varied between 400 and
$1,000 \mu \mathrm{g} \cdot$ day $^{-1}$ of fluticasone propionate (FP) equivalent and no dose-response relationship was apparent [2]. There is, however, a dose-related risk of side-effects, including dysphonia, osteoporosis, cataracts and pneumonia [3,4]. Evidence is scant for an optimal ICS dose that confers long-term benefits whilst minimising potential risks.

COPD is now considered a systemic inflammatory disease. Biomarkers, such as C-reactive protein (CRP), are elevated in COPD and are associated with cardiovascular mortality and recurrent exacerbations [5]. It has been proposed that ICS may 